\title{
Correction to: Experimental investigation for fine finishing of the tapered mould cavity using a newly developed GWMRF process
}

\section{Ankit Aggarwal ${ }^{1} \cdot$ Anant Kumar Singh ${ }^{1}$}

Accepted: 22 September 2021 / Published online: 21 October 2021

(c) The Brazilian Society of Mechanical Sciences and Engineering 2021

\section{Correction to: \\ Journal of the Brazilian Society of Mechanical Sciences and Engineering (2021) 43:444 \\ https://doi.org/10.1007/s40430-021-03159-2}

In the original publication of the article, the Figs. 7, 8, 9 and their captions were wrong. Also the Eq. (7) was also incorrectly published.
The corrected versions are given below.

Finishing rate $=\frac{\left(R a_{i}-R a_{l, f}\right)}{\text { Total time taken for finishing }}$

The original article has also been corrected. 
Fig. 7 Effect of rotation of the CBH type mould cavity $\left(W_{l}\right)$ on $\% \Delta R a_{l}$ at varying (a) reciprocation speed of the GWMRF tool $\left(R_{l}\right),(\mathbf{b})$ current $\left(I_{l}\right)$, and $(\mathbf{c})$ working gap $\left(G_{l}\right)$ during finishing the longitudinal surface of the EN-31 cylindrical blind hole (CBH) type mould cavity using the present GWMRF process (a)

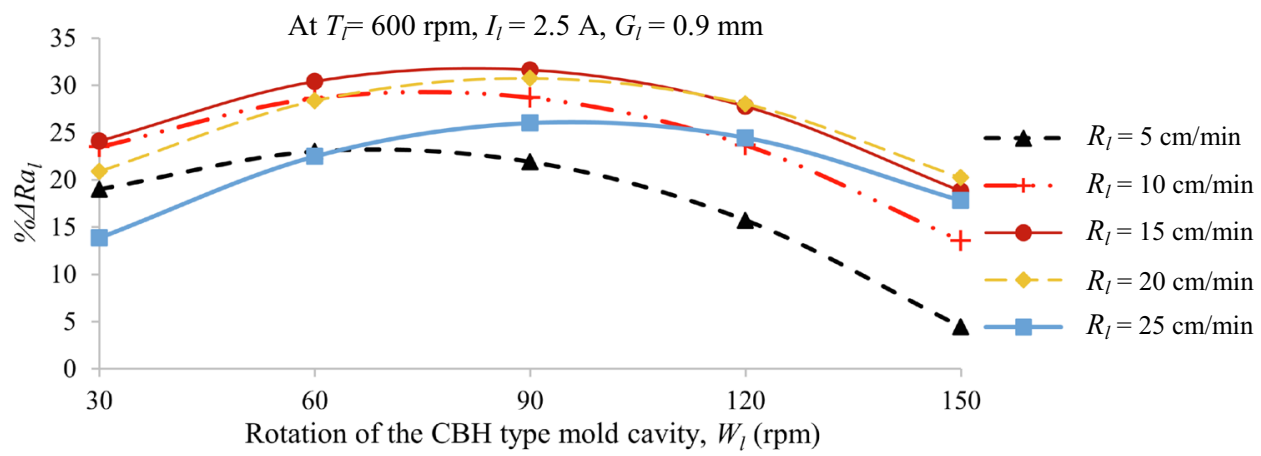

(b)

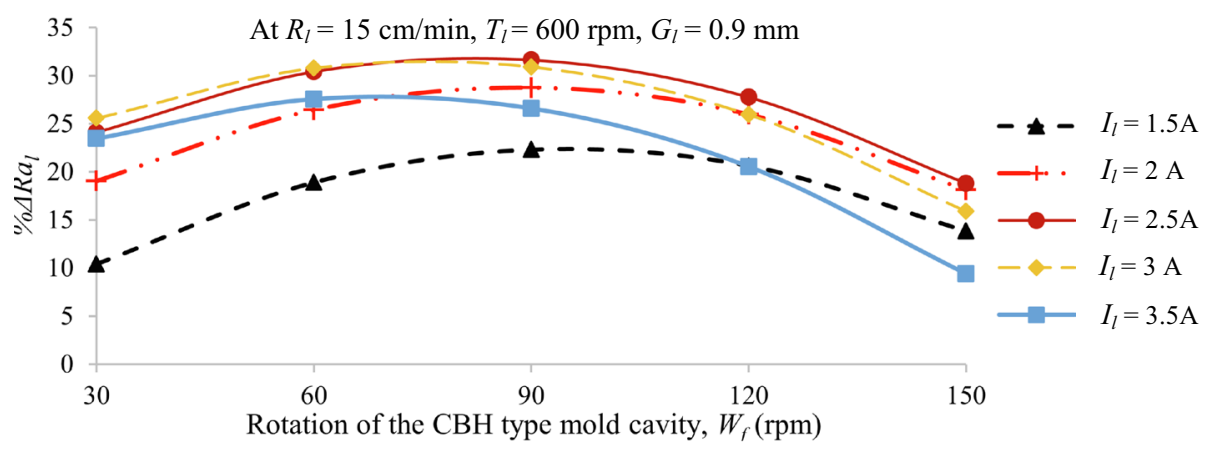

(c)

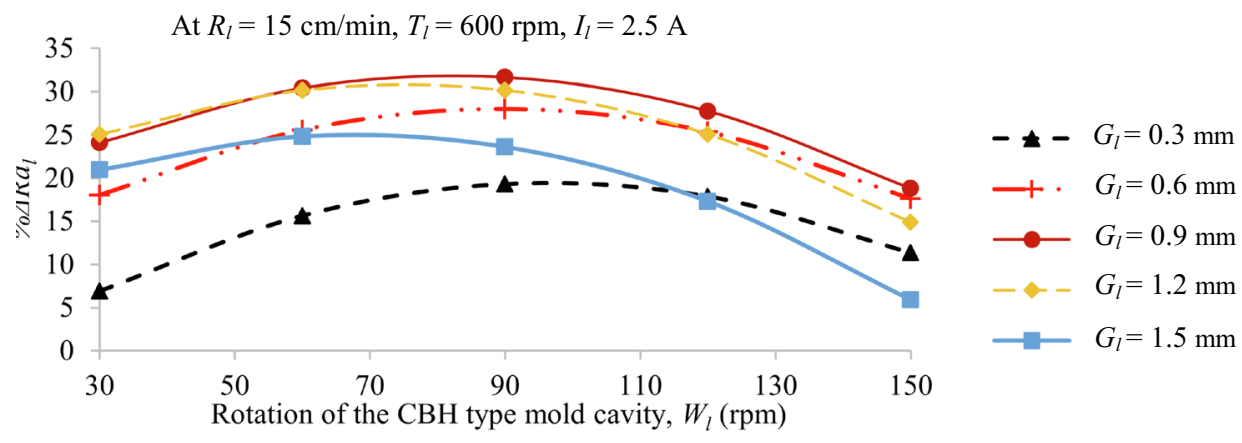


Fig. 8 Effect of GWMRF tool rotation $\left(T_{f}\right)$ on percentage reduction in surface roughness $\left(\% \Delta R a_{f}\right)$ at $(\mathbf{a})$ varying rotation of the cylindrical blind hole $(\mathrm{CBH})$ mould cavity $\left(W_{f}\right)$, (b) reciprocation speed of the GWMRF tool $\left(R_{f}\right),(\mathbf{c})$ varying current $\left(I_{f}\right)$ during finishing over the flat end surface of the EN-31 CBH type mould cavity using the present GWMRF process

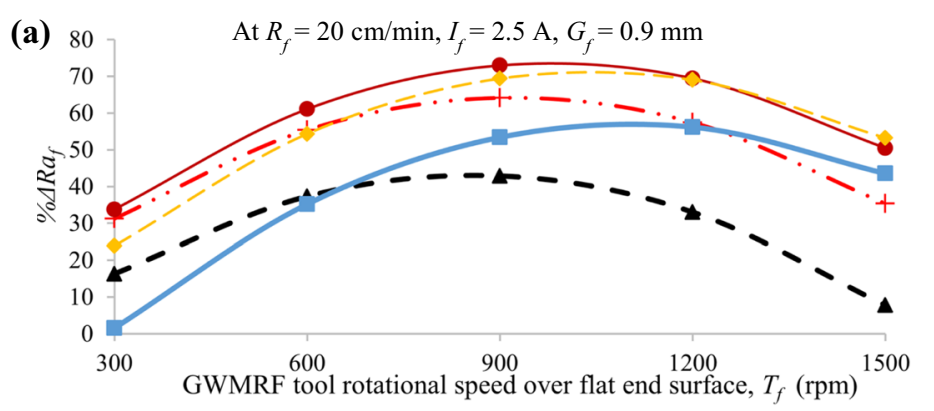

(b)

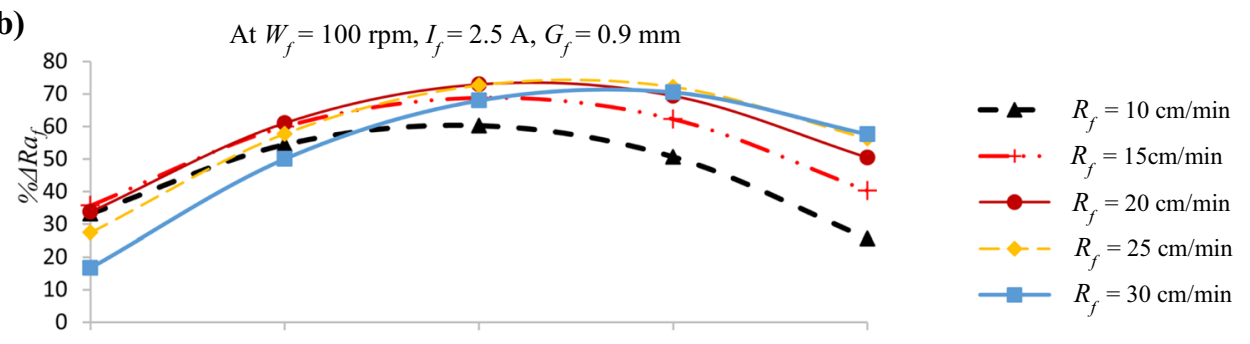

(c)

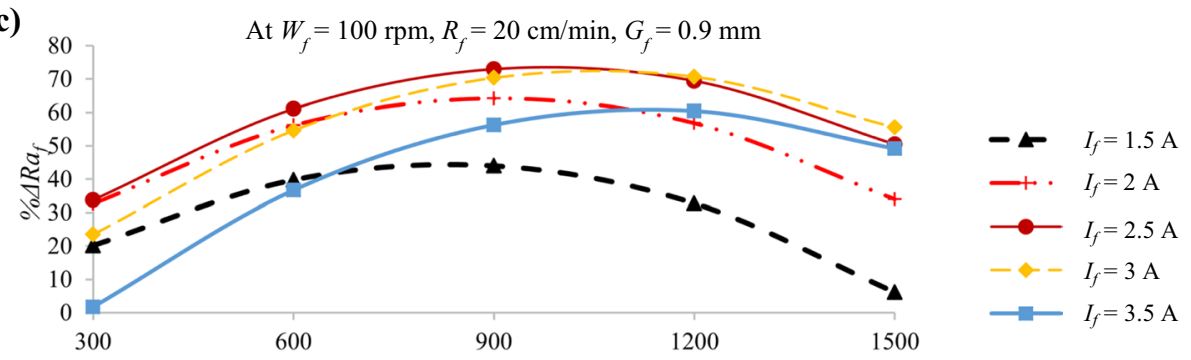

GWMRF tool rotational speed over flat end surface, $T_{f}(\mathrm{rpm})$ 
Fig. 9 (a) Effect of GWMRF tool rotation $\left(T_{f}\right)$ on percentage reduction in surface roughness $\left(\% \Delta R a_{f}\right)$ by varying the working gap $\left(G_{f}\right)$, (b) effect of rotation of the $\mathrm{CBH}$ type mould cavity $\left(W_{f}\right)$ on $\% \Delta R a_{f}$ by varying reciprocation speed of the GWMRF tool $\left(R_{f}\right),(\mathbf{c})$ effect of $R_{f}$ on $\% \Delta R a_{f}$ by varying $G_{f}$ and (d) effect of current $\left(I_{f}\right)$ on $\% \Delta R a_{f}$ by varying $G_{f}$ during finishing over the flat end surface of the EN-31 CBH type mould cavity using the present GWMRF process.
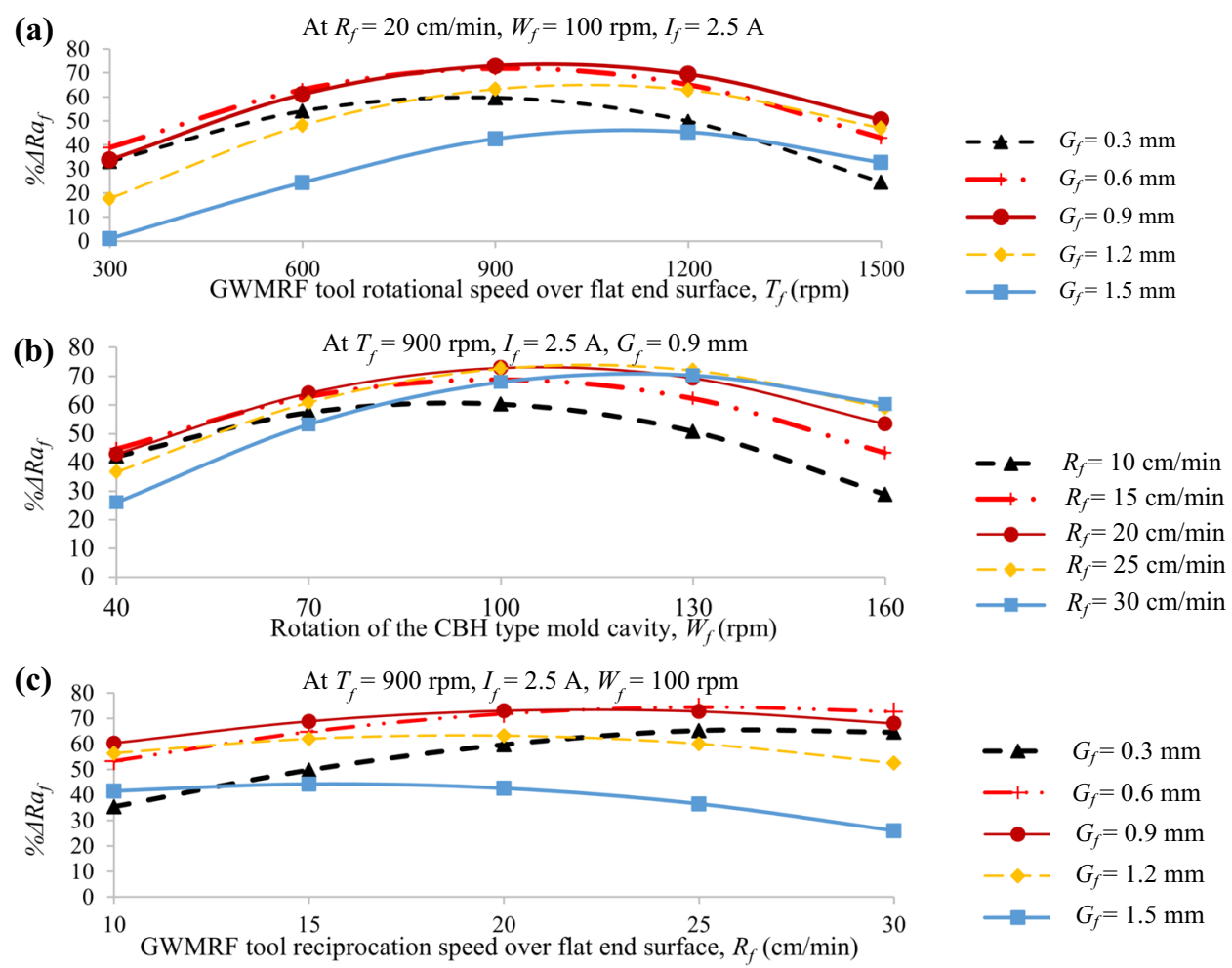

$$
\begin{aligned}
& \text { —ヶ } G_{f}=0.3 \mathrm{~mm} \\
& \text { 一. } G_{f}=0.6 \mathrm{~mm} \\
& \longrightarrow G_{f}=0.9 \mathrm{~mm} \\
& - \text { - } G_{f}=1.2 \mathrm{~mm} \\
& \text { — } G_{f}=1.5 \mathrm{~mm}
\end{aligned}
$$

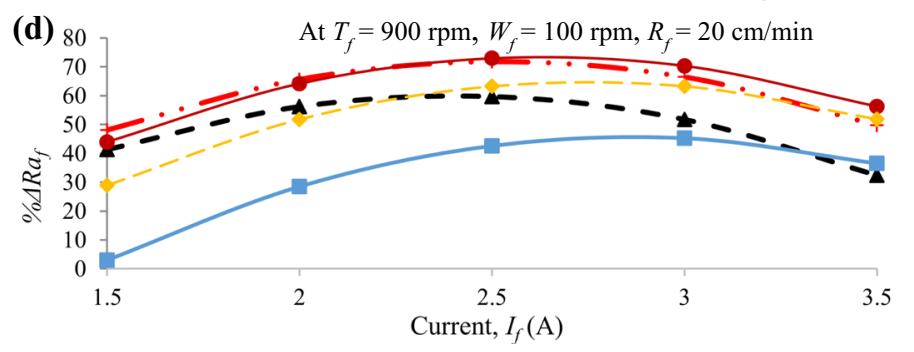

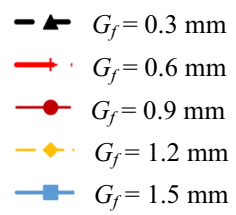

Publisher's Note Springer Nature remains neutral with regard to jurisdictional claims in published maps and institutional affiliations. 